\title{
WEIGHTED NORM INEQUALITIES FOR PARAMETRIC LITTLEWOOD-PALEY OPERATORS
}

\begin{abstract}
Bo LI
Abstract. In this paper, we establish the boundedness of parametric Littlewood-Paley operators from Musielak-Orlicz Hardy space to Musielak-Orlicz space. The endpoint weak type estimates are also obtained. Part of these results are new even for classical Hardy space of Fefferman and Stein.
\end{abstract}

Mathematics subject classification (2010): 42B25, 42B30, 46E30.

Keywords and phrases: Littlewood-Paley operator, Hardy space, Muckenhoupt weight, MusielakOrlicz function.

\section{REFERENCES}

[1] A. Akbulut, V. S. GuliYev And M. DZIRI, Weighted norm inequalities for the g-Littlewood-Paley operators associated with Laplace-Bessel differential operators, Math. Inequal. Appl. 17, (2014), 317 333.

[2] J. CAO, D.-C. Chang, D. YAng And S. YAng, Riesz transform characterizations of MusielakOrlicz-Hardy spaces, Trans. Amer. Math. Soc. 368, (2016), 6979-7018.

[3] R. Coifman And G. Weiss, Extensions of Hardy spaces and their use in analysis, Bull. Amer. Math. Soc. 83, (1977), 569-645.

[4] L. Diening, Maximal function on Musielak-Orlicz spaces and generalized Lebesgue spaces, Bull. Sci. Math. 129, (2005), 657-700.

[5] L. Diening, A. Peter And S. Roudenko, Function spaces of variable smoothness and integrability, J. Funct. Anal. 256, (2009), 1731-1768.

[6] Y. Ding, S. Lu And Q. Xue, Parametrized area integrals on Hardy spaces and weak Hardy spaces, Acta Math. Sin. (Engl. Ser.), 23, (2007), 1537-1552.

[7] Y. Ding, S. Lu And Q. Xue, Parametrized Littlewood-Paley operators on Hardy and weak Hardy spaces, Math. Nachr. 280, (2007), 351-363.

[8] X. FAn, J. HE, B. Li AND D. YANG, Real-variable characterizations of anisotropic product Musielak-Orlicz. Hardy spaces, Sci. China Math. 60, (2017), 2093-2154.

[9] C. FefFerman and E. M. Stein, Some maximal inequalities, Amer. J. Math. 93, (1971), 107-115.

[10] C. FefFerman AND E. M. STein, $H^{p}$ spaces of several variables, Acta Math. 129, (1972), 137-193.

[11] M. FrAZIER, B. JAWERTH AND G. WeISS, Littlewood-Paley theory and the study of function spaces, CBMS Regional Conference Series in Mathematics 79, Published for the Conference Board of the Mathematical Sciences, Washington, DC; by the American Mathematical Society, Providence, RI, 1991. viii+132 pp.

[12] L. Grafakos, Classical Fourier Analysis, Second edition, Graduate Texts in Mathematics, Vol. 249, Springer, New York, 2009.

[13] G. H. Hardy, The mean value of the modulus of an analytic function, Proc. Lond. Math. Soc. 14, (1914), 269-277.

[14] R. Jiang, D. Yang And Y. Zhou, Orlicz-Hardy spaces associated with operators, Sci. China Ser. A, 52, (2009), 1042-1080.

[15] R. JiAng AND D. YANG, New Orlicz-Hardy spaces associated with divergence form elliptic operators, J. Funct. Anal. 258, (2010), 1167-1224. 
[16] R. Jiang And D. YAng, Predual spaces of Banach completions of Orlicz-Hardy spaces associated with operators, J. Fourier Anal. Appl. 17, (2011), 1-35.

[17] R. JiAng AND D. YANG, Orlicz-Hardy spaces associated with operators satisfying Davies-Gaffney estimates, Commun. Contemp. Math. 13, (2011), 331-373.

[18] R. L. Johnson and C. J. Neugebauer, Homeomorphisms preserving $A_{p}$, Rev. Mat. Iberoamericana 3, (1987), 249-273.

[19] L. D. Ky, New Hardy spaces of Musielak-Orlicz, type and boundedness of sublinear operators, Integral Equations Operator Theory 78, (2014), 115-150.

[20] B. LI, X. FAN AND D. YANG, Littlewood-Paley characterizations of anisotropic Hardy spaces of Musielak-Orlicz type, Taiwanese J. Math. 19, (2015), 279-314.

[21] B. LI, X. FAn, Z. FU AND D. YANG, Molecular characterization of anisotropic Musielak-Orlicz Hardy spaces and their applications, Acta Math. Sin. (Engl. Ser.), 32, (2016), 1391-1414.

[22] B. LI, M. LIAO AND B. LI, Boundedness of Marcinkiewicz integrals with rough kernels on MusielakOrlicz Hardy spaces, J. Inequal. Appl. 2017, (2017), 228.

[23] Y. Liang, J. HuAng And D. YANG, New real-variable characterizations of Musielak-Orlicz Hardy spaces, J. Math. Anal. Appl. 395, (2012), 413-428.

[24] Y. Liang And D. YAng, Musielak-Orlicz Campanato spaces and applications, J. Math. Anal. Appl. 406, (2013), 307-322.

[25] Y. Liang, D. YAng And R. JiAng, Weak Musielak-Orlicz Hardy spaces and applications, Math. Nachr. 289, (2016), 634-677.

[26] F. LiU, On the Triebel-Lizorkin space boundedness of Marcinkiewicz integrals along compound surfaces, Math. Inequal. Appl. 20, (2017), 515-535.

[27] F. LiU AND H. WU, On the $L^{2}$ boundedness for the multiple Littlewood-Paley functions with rough kernels, J. Math. Anal. Appl. 410, (2014), 403-410.

[28] F. LiU, H. WU AND D. ZhANG, $L^{p}$ bounds for parametric Marcinkiewicz integrals with mixed homogeneity, Math. Inequal. Appl. 18, (2015), 453-469.

[29] X. LiU, B. LI, X, QIU AND B. LI, Estimates for parametric Marcinkiewicz integrals on MusielakOrlicz Hardy spaces, J. Math. Inequal. 12, (2018), 1117-1147.

[30] M. Sakamoto And K. Yabuta, Boundedness of Marcinkiewicz functions, Studia Math. 135, (1999), 103-142.

[31] S. Shi, Q. XUE And K. YABUtA, On the boundedness of multilinear Littlewood-Paley $g_{\lambda}^{*}$ function, J. Math. Pures Appl. (9), 101, (2014), 394-413.

[32] J.-O. Strömberg AND A. TorChinsky, Weighted Hardy spaces, Lecture Notes in Mathematics Vol. 1381, Springer-Verlag, Berlin, 1989.

[33] Q. Xue AND Y. Ding, Weighted $L^{p}$ boundedness for parametrized Littlewood-Paley operators, Taiwanese J. Math. 11, (2007), 1143-1165.

[34] Q. Xue, K. Yabuta And J. Yan, On the boundedness of fractional type Marcinkiewicz integral operators, Math. Inequal. Appl. 18, (2015), 519-527.

[35] D. YAng, Y. LiAng AND L. D. Ky, Real-Variable Theory of Musielak-Orlicz Hardy spaces, Lecture Notes in Mathematics Vol. 2182, Springer, Cham, 2017.

[36] D. Yang, W. Yuan And C. Zhuo, Musielak-Orlicz Besov-type and Triebel-Lizorkin-type spaces, Rev. Mat. Complut. 27, (2014), 93-157.

[37] H. Zhang, C. QI AND B. LI, Anisotropic weak Hardy spaces of Musielak-Orlicz type and their applications, Front. Math. China 12, (2017), 993-1022. 